\title{
Cough in hypereosinophilic syndrome: case report and literature review
}

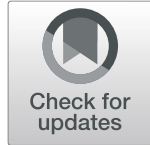

\author{
Jiaxing Xie ${ }^{1}$, Jianheng Zhang ${ }^{1}$, Xiaoxian Zhang ${ }^{1}$, Qingling Zhang ${ }^{1}$, Kian Fan Chung ${ }^{2}$, Chunyan Wang ${ }^{3^{*}}$ and \\ Kefang Lai $^{4^{*}}$
}

\begin{abstract}
Background: Cough and airway eosinophilic inflammation has not been highlighted in hypereosinophilic syndrome (HES).

Case presentation: We report 2 further cases and reviewed the clinical features and treatment of HES present with cough from the literature. Both cases were middle age male, presenting with chronic cough, airway eosinophilic inflammation and hyper eosinophilia who have been previous misdiagnosed as cough-variant asthma and failed anti-asthma treatment. PDGFRA fusion gene was confirmed in one case, but not in the other case. Both had evidence of myeloproliferative features. The tyrosine kinase inhibitor, imatinib, resulted in complete resolution of eosinophilia and cough. By searching PubMed, we found 8 HES cohorts of 411 cases between 1975 and 2013, where the incidence of cough was $23.11 \%$. Sixteen case reports of HES presented with cough as predominant or sole symptom, with nine male patients with positive PDGFRA fusion gene, who responded well to imatinib. Six of seven patients, who tested negative for the PDGFRA, responded to systemic glucocorticoids.
\end{abstract}

Conclusions: Cough and airway eosinophilic inflammation is common in some HES patients. PDGFRA+ HES patients present with chronic cough respond well to imatinib. Our case reports indicate that PDGFRA negative HES patients may respond to imatinib as well.

Keywords: Airway eosinophilic inflammation, Cough, Hypereosinophilic syndrome, Imatinib, PDGFRA fusion gene

\section{Background}

Chronic cough is defined as the sole or predominant symptom and lasting for more than 8 weeks, with a normal chest $\mathrm{x}$-ray [1]. The common causes of chronic cough are cough-variant asthma (CVA), nonasthmatic eosinophilic bronchitis (NAEB), upper airway cough syndrome and gastroesophageal reflux disease (GERD) [2]. Eosinophilic airway inflammation

\footnotetext{
*Correspondence: wcy163@163.com; klai@163.com

${ }^{3}$ Department of hematology, The First Affiliated Hospital of Guangzhou Medical University, 1 Kangda Road, Guangzhou 510230, China

${ }^{4}$ National Clinical Research Center for Respiratory Disease, State Key Laboratory of Respiratory Disease, Guangzhou Institute of Respiratory Health, the First Affiliated Hospital of Guangzhou Medical University, 151 Yanjiang Road, Guangzhou 510120, China

Full list of author information is available at the end of the article
}

is commonly observed in chronic cough, usually responding to corticosteroids [3].

Recently, two outstanding reviews $[4,5]$ describe the emerging role of eosinophilic inflammation in chronic cough, new insights on its mechanisms and available treatments. These two reviews basically focused on eosinophilic airway inflammation in asthma, nonasthmatic eosinophilic bronchitis, and upper airway cough syndrome. However, the hypereosinophilic syndrome (HES) could be a rare and long-ignored cause of chronic cough. HES comprises a heterogeneous group of hematologic disorders characterized by unexplained sustained eosinophilia ( $>1500 / \mu \mathrm{L}$ for more than 6 months) associated with signs and symptoms of organ involvement [6]. While HES is a rare disease, HES presenting with chronic cough as the main symptom is even rarer.

(c) The Author(s). 2020 Open Access This article is licensed under a Creative Commons Attribution 4.0 International License, which permits use, sharing, adaptation, distribution and reproduction in any medium or format, as long as you give appropriate credit to the original author(s) and the source, provide a link to the Creative Commons licence, and indicate if changes were made. The images or other third party material in this article are included in the article's Creative Commons licence, unless indicated otherwise in a credit line to the material. If material is not included in the article's Creative Commons licence and your intended use is not permitted by statutory regulation or exceeds the permitted use, you will need to obtain permission directly from the copyright holder. To view a copy of this licence, visit http://creativecommons.org/licenses/by/4.0/ The Creative Commons Public Domain Dedication waiver (http://creativecommons.org/publicdomain/zero/1.0/) applies to the data made available in this article, unless otherwise stated in a credit line to the data. 
HES patients may have eosinophilic infiltrates in the airways, and are often misdiagnosed as CVA, asthma, or other eosinophilic lung diseases. Chronic cough as presenting manifestation of platelet-derived growth factor receptor alpha (PDGFRA) + chronic eosinophilic leukaemia is being increasingly recognized [7]. Recently, we successfully treated 2 patients with HES, eosinophilic airway inflammation, and chronic cough, in whom one was PDGFRA +, but the other was not. We report both cases and reviewed all published cases and cohorts in literature to learn more about the features of HESassociated cough.

\section{Case presentation \\ Case 1}

The patient was a 41-year-old male with 20 pack-years smoking history who complained of a chronic cough that had lasted for more than 2 years with shortness of breath, for 6 months. His cough was worse at night and was aggravated in the supine position. Auscultation of the lung was normal. There was a grade 3 systolic murmur at the apex and in the area of the tricuspid valve and mild pitting edema was seen in both lower limbs. The blood eosinophil count was $7510 / \mu \mathrm{L}$. The cardiac shadow was enlarged, and there was a small pericardial effusion in chest computed tomography (CT). Forced expiratory volume in the first second $\left(\mathrm{FEV}_{1}\right)$ was $97.63 \%$ of predicted value, with $\mathrm{FEV}_{1} / \mathrm{FVC}$ was $100.97 \%$. Peak expiratory flow variability over 1 week was $27 \%$. Bronchoscopy was normal, but bronchoalveolar lavage fluid
(BALF) indicated 28\% eosinophils. Total IgE was 26.1 $\mathrm{kU} / \mathrm{L}$. CVA was initially suspected by another respirologist who performed initial diagnostic workups including bronchoscopy according to the presence of airway reversibility and airway eosinophilia. Methylprednisolone at $80 \mathrm{mg} / \mathrm{d}$ IV and bronchodilators were given. But the symptoms did not improve, and the eosinophil count remained elevated at $10,700 / \mu \mathrm{L}$. He was referred to our hospital. The B-type natriuretic peptide (BNP) was 4776 $\mathrm{pg} / \mathrm{mL}$, and the antineutrophil cytoplasmic antibody was negative. Cardiac magnetic resonance imaging showed hypertrophic cardiomyopathy. Coronary angiography showed no significant stenosis in the coronary arteries. Abdominal ultrasound showed an abdominal effusion and splenomegaly. The patient was treated with inhaled corticosteroids (ICS), cardiotonic drugs, and diuretics, leading to a slight improvement in symptoms. Antibody for both paragonimiasis and liver flukes were positive. Praziquantel was given, without improvement. The bone marrow cytology showed eosinophilia (37.5\%). The test for the PDGFRA fusion gene mutation was positive (Fig. 1). Imatinib tablets $100 \mathrm{mg}$ daily were given. Because the patient had cardiac involvement and elevated BNP level, dexamethasone $10 \mathrm{mg}$ daily was administered at the same time. The dose of corticosteroid was gradually tapered off. The patient's dry cough and shortness of breath were relieved. The blood eosinophil dropped to $60 / \mu \mathrm{L}$. An echocardiogram was repeated 4 months after discharge and showed no improvement. Mitral tricuspid valve angioplasty was performed, with

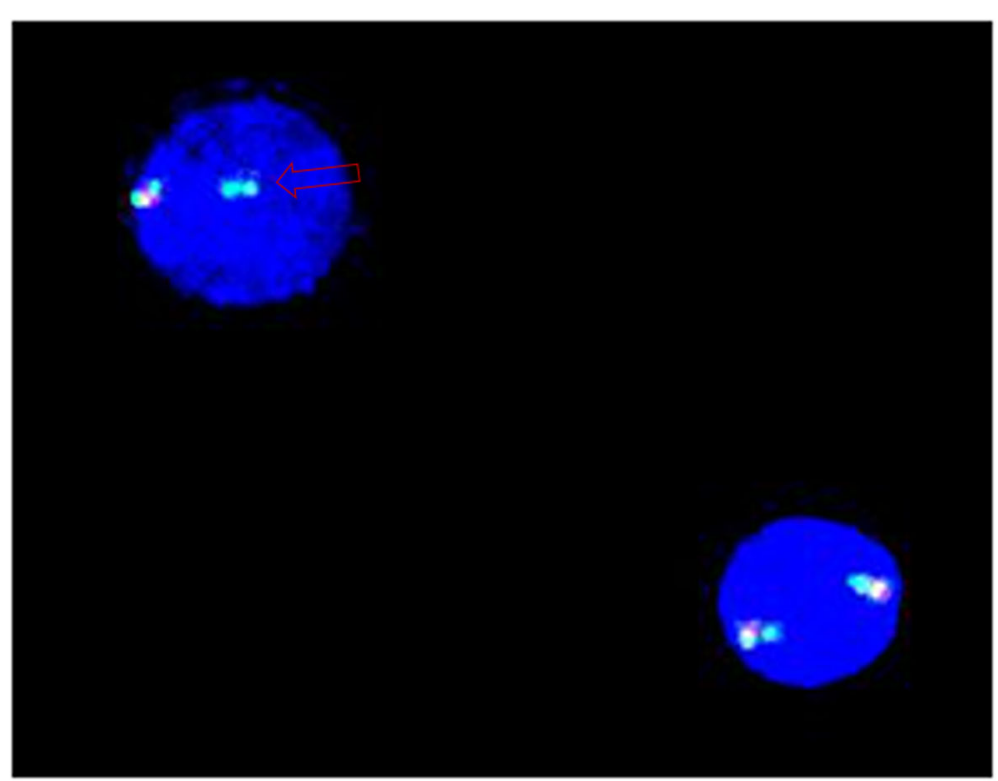

Fig. 1 Fluorescence in situ hybridisation (FISH) analysis of case 1. Absence of the CHIC2 region was observed as loss of a red signal (arrow) from the co-localized green/green signal, indicative of the presence of this specific deletion that leads to FIP1L1-PDGFRA fusion on one of the chromosomes 4 
improvement of his cardiac function. The final diagnosis was myeloid and lymphoid neoplasm associated with eosinophilia and PDGFRA rearrangement.

\section{Case 2}

The patient was a nonsmoker 52-year-old male with a chronic productive cough for 7 years after moving into a new office. The cough was more pronounced during the night and worsened on exposure to cigarette smoke. The sputum was white and sticky and not easy to cough up. At that time blood eosinophils count was 2220/ $\mathrm{uL}(36.2 \%) . \mathrm{FEV}_{1}$ was $98.3 \%$ of predicted value. $\mathrm{FEV}_{1} /$ FVC was $70.04 \%$. The methacholine $(\mathrm{MCh})$ challenge test was positive $\left(\mathrm{PD}_{20}=2.504 \mathrm{mg}\right)$. The induced sputum eosinophil count was $64 \%$. The patient was diagnosed as CVA and treated with inhaled budesonide formoterol, but his symptoms did not improve. He was then given oral montelukast sodium and prednisone $10 \mathrm{mg}$ daily and his symptoms improved slightly. However, his eosinophil count did not decrease. He was then admitted to the hematology department. The bone marrow biopsy showed eosinophilia. Prednisone $40 \mathrm{mg}$ daily was given, and the cough was slightly improved. The patient continued to take prednisone intermittently for 4 years. However, his eosinophil count was still up to $4020 / \mu \mathrm{L}$. The patient was admitted to the respiratory department of our hospital due to cough and hyper eosinophilia. Dry rales were heard on exhalation. The blood eosinophil was $1550 / \mathrm{uL}(27.0 \%)$. No abnormalities were found on a CT of the paranasal sinuses. The chest CT showed multiple scattered nodules in both lungs (Fig. 2). The T total IgE was $157 \mathrm{kU} / \mathrm{L}$. BNP and troponin were normal. The induced sputum eosinophil count was $18.5 \%$. Fractional exhaled nitric oxide (FeNO) was 96 ppb. $\mathrm{FEV}_{1}$ was $110 \%$ of predicted value. $\mathrm{FEV}_{1} / \mathrm{FVC}$ was $70.84 \%$. The $\mathrm{MCh}$ bronchial challenge test was positive $\left(\mathrm{PD}_{20}=1.877 \mathrm{mg}\right)$. Biopsy of the bronchial mucosa and gastric mucosa showed eosinophilic infiltration. The ultrasound indicated splenomegaly (126 mm long). Parasite antibodies were negative. Since the patient had a history of eating raw river fish, he was given albendazole 0.4 daily for 1 week and inhaled beclomethasone/formoterol. There was no significant remission of cough and no decrease in the eosinophil count. Finally, he was transferred to the hematology department. An ultrasound indicated that the spleen (142 $\mathrm{mm}$ long) was larger than previously. The bone marrow aspiration showed eosinophilia. The eosinophil percentage in the peripheral blood was $28 \%$, and precursors were also seen. Examination for PDGFRa, PDGFRb, FGFR, JAK2 or FLT3 fusion genes proved negative. Imatinib $0.1 \mathrm{~g}$ per week was given, and the cough subsided significantly 1 month after this treatment. Two months later blood eosinophil was 120/ $\mathrm{uL}(2 \%)$. At the final follow up the cough was completely relieved for the first time in 7 years. This patient was diagnosed as PDGFRA negative HES associated myeloid neoplasm (MHES).

\section{Literature search strategy and terms}

For the literature review, we used the PubMed database. Papers written in English were selected. Main search terms were hypereosinophilic syndrome and cough. Additional papers were included by reviewing the references of the primarily selected papers with the same criteria. Cases with recognized pediatric HES, specific disease entities including Churg Strauss vasculitis, acute or chronic

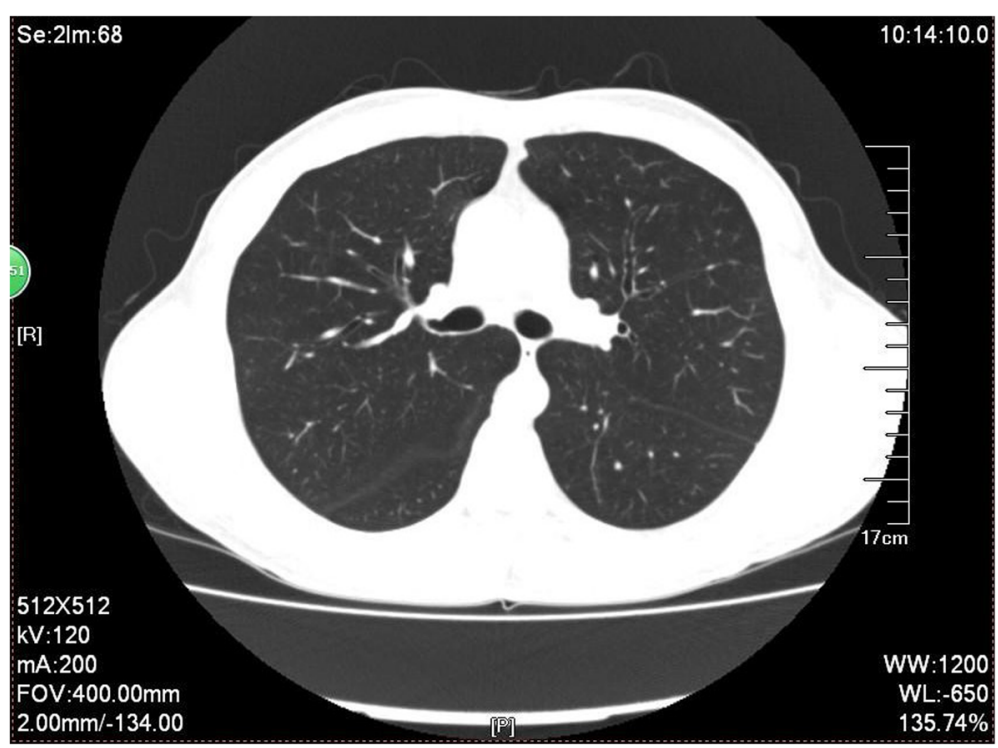

Fig. 2 The chest $C T$ of case 2 . The chest $C T$ showed multiple scattered nodules in both lungs 
eosinophilic pneumonia, allergic bronchopulmonary aspergillosis, and other secondary hypereosinophilia were excluded.

Eight cohorts of HES patients consisting of 411 cases were retrieved from PubMed [8-15] (Table 1). The lung involvement ranged from 25 to $67 \%$ (37.77\%), with an incidence of cough ranging from 10 to $41 \%$ (23.11\%). In 2 of the 8 studies, 69 patients, all male, were positive for the PDGFRA fusion gene $[8,9]$ with the incidence of cough being $37.68 \%$. In 2 other studies, positivity for the PDGFRA fusion gene was lower (about 10\%) [10, 11], with ratio of male to female being similar, and the incidence of cough was $20.67 \%$. Four studies were reported in the 1970s and 1980s [12-15], at that time no method for the detection of the PDGFRA fusion gene was available. The cough incidence in these 4 studies was $29.52 \%$. In the aforementioned cohorts, no measurement of airway eosinophilia was performed to assess the severity of eosinophilic inflammation.

We found 16 HES cases [7, 16-30] with cough as the main or only symptom (Case $3-18$, Table 2 ). The overall clinical information is summarized in Table 2 . The average age was 53.6 years, and the male-to-female ratio was 13:3. There were 2 current smokers, 1 ex-smoker, 5 nonsmokers, and 6 unknown status. All patients had elevated blood eosinophil counts, with an average of 7800/ $u L$. The eosinophils in BALF were significantly elevated when evaluated, ranging from 20 to $84 \%$.

Nine of twelve cases evaluated were found to have PDGFRA fusion gene (case 3-11). There were 10 HES cases with PDGFRA fusion gene include our cases (case 1 , Table 2), all of them had chronic cough as the main or sole manifestation. They were all male with an average age of 47.7 years. In five cases where total IgE was measured, this was not high. All except case 9 and case11 had normal spirometry. Only two cases (case 4 and 5) performed airway responsiveness test, case 5 had marked bronchial hyperreactivity. Six cases had chest X ray, and 4 cases had normal chest X-ray. Only case 1 and 3 had performed induced sputum test and had significant sputum eosinophils. Another two cases had significantly increased eosinophils in BALF (27\% in case $1,20 \%$ in case 5 ). On airway mucosal biopsy, 2 cases showed eosinophil infiltration in the airway mucosa (case 3 and 4). All cases had been transferred to a number of hospitals and had been alternatively diagnosed with asthma, GERD, pneumonia, and other diseases. Five of them received oral corticosteroids (OCS) (case 1,3, 4, 6, and 9). Three received ICS (cases 1,3 and 5). Two received proton pump inhibitors (cases 4 and 5), and two cases received experimental antiparasitic treatment (cases 1 and 4). All these treatments were ineffective. Eventually, imatinib was given and proved to be effective. Case Two in our study had severe and persistent airway eosinophil inflammation, persistent bronchial hyperreactivity, negative fusion genes and was steroid (OCS and ICS) refractory, but he showed features suggestive of a myeloproliferative neoplasm (progressive splenomegaly and presence of early myeloid precursors on the peripheral smear). We reviewed the clinical feature of case 12 in Table 2 and found it consistent with MHES too. The cough of this case resolved within 3 days of imatinib, and his diffusion capacity, lung volumes and interstitial infiltrates in CT normalized after 3 months of imatinib therapy.

In other six patients $[23-28,30]$, three showed negative PDGFRA fusion gene (cases 14 to 16 ), and another 3 patients did not have fusion gene examination. The male-to-female ratio was $4: 3$, and the mean age was 61.3 years. Almost all cases had abnormal chest $\mathrm{X}$ ray. Only two cases had performed BALF and showed significantly increased eosinophils (73\% in case $13,84 \%$ in case 15). There were 4 cases with cardiac dysfunction. The main treatment was systemic glucocorticoids. After treatment, cough and other symptoms were relieved. However, 4 cases (case 13, 15, 17, and 18) relapsed after the corticosteroid was tapered off. In case 16, her symptom and eosinophilia persisted despite sequential trials of imatinib and interferon- $\alpha$, but a trial of mepolizumab was effective.

Table 1 Frequency of pulmonary involvement and cough in HES from 6 series

\begin{tabular}{llllllll}
\hline Author & Year of publication & Cases & Sex (M/F) & Age (y) & Pulmonary involvement (\%) & Cough (\%) & PDGFRA fusion gene positive (\%) \\
\hline Helbig [5] & 2013 & 25 & $23 / 2$ & NA & NA & $8 / 25(32)$ & $25 / 25(100)$ \\
Legrand [6] & 2013 & 44 & $43 / 1$ & $41(6-67)^{\text {a }}$ & $20 / 44(45)$ & $18 / 44(41)$ & $44 / 44(100)$ \\
Dulohery [7] & 2011 & 49 & $25 / 24$ & $50(12-88)^{a}$ & $33 / 49(67)$ & $19 / 49(39)$ & $4 / 49(8)$ \\
Ogbogu [8] & 2009 & 188 & $104 / 84$ & $45(6-85)^{\text {a }}$ & $47 / 188(25)$ & $19 / 188(10)$ & $18 / 161(11)$ \\
Spry [11] & 1983 & 15 & $13 / 2$ & 32.2 & $12 / 15(40)$ & $12 / 15(40)$ & NA \\
Fauci [9] & 1982 & 50 & NA & $33^{\mathrm{b}}$ & $20 / 50(40)$ & $12 / 50(24)$ & NA \\
Parrilo [12] & 1979 & 26 & NA & NA & NA & $3 / 26(12)$ & NA \\
Chusid [10] & 1975 & 14 & $14 / 0$ & $37.5^{b}$ & $6 / 14(43)$ & $4 / 14(29)$ & NA \\
\hline
\end{tabular}




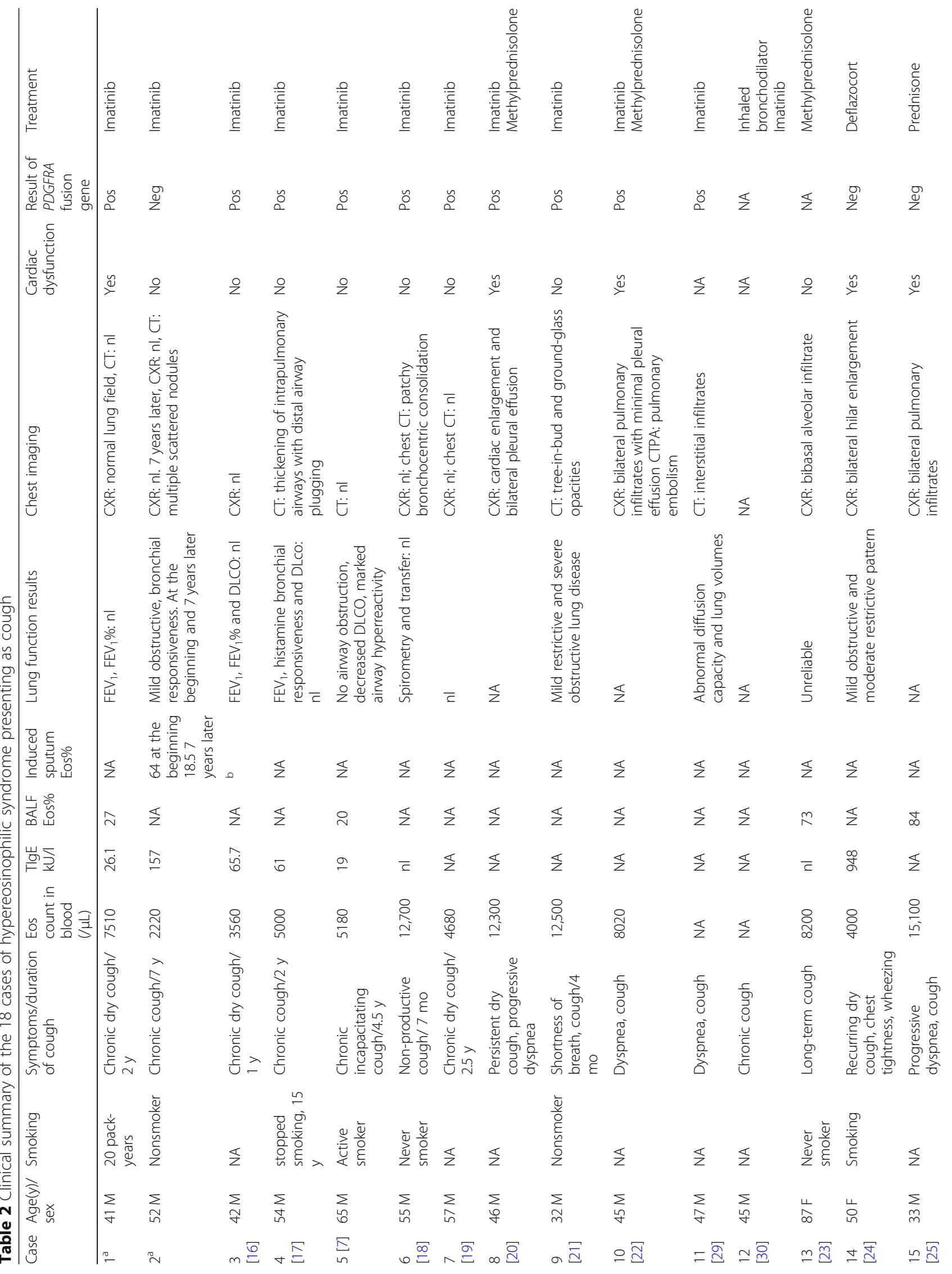




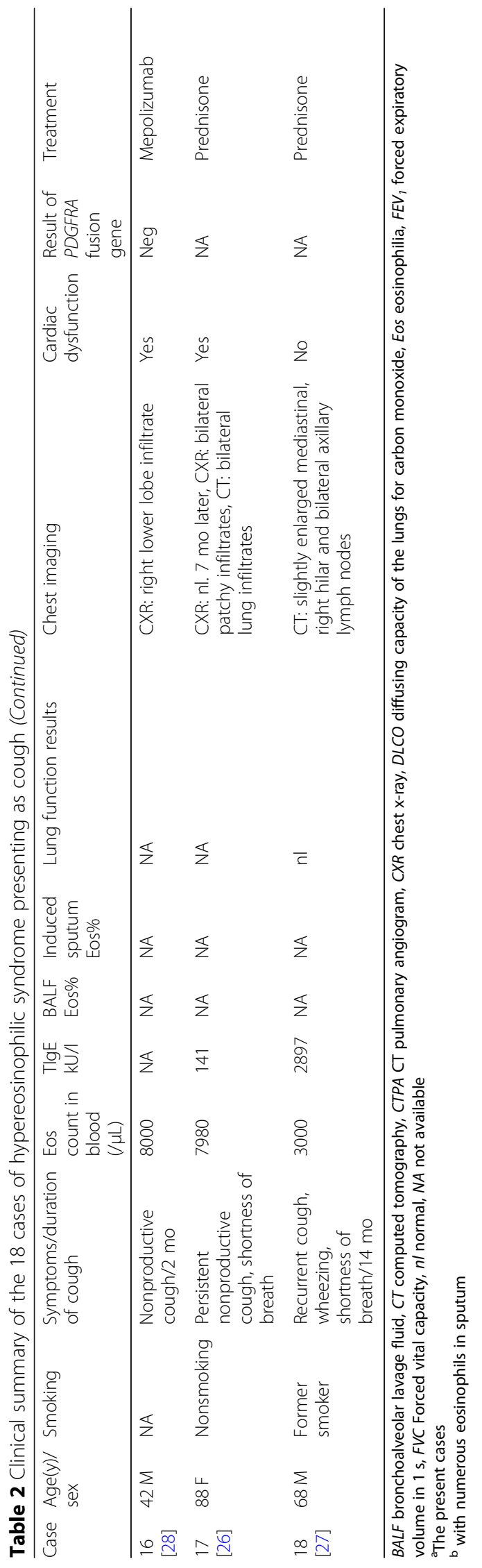




\section{Discussion and conclusions}

In recent years, with the availability of PDGFRA fusion gene examination, more HES patients who test positive for this gene have been identified. These patients have often spent years with a misdiagnosis. It is important to clarify whether there is a rearrangement of the fusion gene by early fluorescence in situ hybridization (FISH) or nested RT-PCR testing [31] after eliminating secondary causes of eosinophilia. Because eosinophil autofluorescence may interfere with FISH, Roufosse et al. [7] recommended that both FISH and RT-PCR should be performed when this disease is suspected. Imatinib was curative in HES patients with a positive PDGFRA fusion gene, and there was no relapse report. Cardiac structural abnormalities may not improve with imatinib therapy [32], case one didn't show improvement in cardiac ultrasound after 4 month imatinib and needed mitral tricuspid valve angioplasty. Currently all HES-associated chronic cough cases have only PDGFRA fusion gene rearrangements. The other fusion genes rearrangements, such as PDGFRB, FGFR1, and JAK2 have not been reported in HES-associated cough cases.

Recently Khoury and Klion et al. [33, 34] proposed PDGFRA-negative HES with features suggestive of a myeloproliferative neoplasm (MHES), these patients have splenomegaly, presence of early myeloid precursors on the peripheral smear, elevated serum B12, and/or Tryptase levels, and resistance to corticosteroid therapy. They performed a prospective study of imatinib in HES, found clinical features of MHES predict imatinib response in PDGFRA negative HES [33]. Our Case 2 is consistent with MHES. The effect of imatinib is obvious, confirming the great possibility of MHES.

The HES patients without the PDGFRA fusion gene are commonly treated with systemic glucocorticoids, though the recurrence rate is high. The treatment of targeted eosinophil depletion, as with the monoclonal antiinterleukin-5 antibody mepolizumab, can be considered. Although previous studies found that mepolizumab failed to reduce cough in patients with refractory eosinophilic asthma [35], it was effective in case 16 [28]. Mepolizumab may become a treatment option for HES patients without the PDGFRA fusion gene.

Because the lung is one of the common involved organ of HES, biomarkers of airway eosinophilic inflammation such as FENO, induced sputum, BALF should be recommended in this condition. In Table 2, biomarkers of airway eosinophilic inflammation were measured only in seven patients, and all had increased eosinophil numbers. The cause of cough in HES patients may be associated with high airway and blood eosinophil counts. The cough may be caused by thickening of the basement membrane, goblet cell hyperplasia, or airway eosinophil inflammation [36]. The mast cells may also be involved in the occurrence of cough and be the target of imatinib. It has been confirmed that numbers of active mast cells appear in the bone marrow of HES patients with a positive PDGFRA fusion gene [34]. The mechanisms underlying eosinophilic airway inflammation in chronic cough due to allergic ( $\mathrm{T}$ helper type 2 cells) and nonallergic (innate lymphoid type 2 cells) pathways had been illustrated in 2 recent outstanding reviews $[4,5]$. Activated $\mathrm{T}$ helper type 2 or innate lymphoid type 2 cells release interleukins, causing eosinophilia inflammation, and bronchial hyperreactivity. Although PDGFRA+ HES or MHES (case 1-12, Table 2) could showed bronchial hyperreactivity, they had no response to OCS and ICS. It seems no allergic triggers contribute to the pathogenesis. The mechanism underlying eosinophilic airway inflammation and bronchial hyperreactivity warrants further investigation.

In addition, the heart is also one of the most commonly affected organs in HES patients. Our review of the literature found that 7 patients $(46.6 \%)$ with normal lung function had cardiac insufficiency. The pulmonary edema caused by cardiac insufficiency might be the cause of cough.

In conclusion, cough is one of the main symptoms in HES patients. Eosinophilic airway inflammation and bronchial hyperreactivity are observed in some HES patients and don't response to corticosteroids. A screening test for the PDGFRA fusion gene is essential for patients with increased eosinophils, especially if they are male. For the PDGFRA negative ones, MHES should be evaluated. Our case report indicates that cough and eosinophilic airway inflammation in PDGFRA negative HES may respond to imatinib as well. Taken together, we suggest the importance of rapid and correct diagnosis of HES and MHES, particularly when only cough or other nonspecific symptoms are present.

\section{Abbreviations \\ BALF: Bronchoalveolar lavage fluid; BNP: B-type natriuretic peptide; CT: Computed tomography; CVA: Cough-variant asthma; FENO: Fractional exhaled nitric oxide; $F V_{1}$ : Forced expiratory volume in the first second: FVC: Forced vital capacity; FISH: Fluorescence in situ hybridization; GERD: Gastroesophageal reflux disease; HES: Hypereosinophilic syndrome; ICS: Inhaled corticosteroids; MCh: Methacholine; MHES: PDGFRA negative HES associated myeloid neoplasm; NAEB: Non-asthmatic eosinophilic bronchitis; OCS: Oral corticosteroids}

\section{Acknowledgements}

Not applicable.

Authors' contributions

$J X$ analyzed, interpreted the patient data, performed the literature review and drafted the manuscript. JX, JZ, XZ and CW were responsible for patient management. $\mathrm{KC}, \mathrm{QZ}, \mathrm{CW}$ and $\mathrm{KL}$ critically revised the manuscript. All authors read and approved the final manuscript.

\section{Funding}

This work was supported by "Professor K.F. Chung's Visiting Professor Project of Guangzhou Institute of Respiratory Health (grant 
no.500102010501069001)". The funders had no role in study design, data collection and analysis, decision to publish, or preparation of the manuscript.

\section{Availability of data and materials}

All data discussed in the manuscript are included within this published article.

\section{Ethics approval and consent to participate} Not applicable.

\section{Consent for publication}

Written informed consent was obtained from the patients for publication of this case report.

\section{Competing interests}

The authors declare that they have no competing interests.

\section{Author details \\ 'Department of Allergy and Clinical Immunology, National Clinical Research Center for Respiratory Disease, State Key Laboratory of Respiratory Diseases, Guangzhou Institute of Respiratory Health, The First Affiliated Hospital of Guangzhou Medical University, Guangzhou, China. ${ }^{2}$ National Heart and Lung Institute, Imperial College London \& Royal Brompton Biomedical Research Unit at Royal Brompton and Harefield NHS Foundation Trust, London, UK. ${ }^{3}$ Department of hematology, The First Affiliated Hospital of Guangzhou Medical University, 1 Kangda Road, Guangzhou 510230, China. ${ }^{4}$ National Clinical Research Center for Respiratory Disease, State Key Laboratory of Respiratory Disease, Guangzhou Institute of Respiratory Health, the First Affiliated Hospital of Guangzhou Medical University, 151 Yanjiang Road, Guangzhou 510120, China.}

\section{Received: 11 October 2019 Accepted: 3 April 2020}

\section{Published online: 15 April 2020}

\section{References}

1. Lalloo UG, Barnes PJ, Chung KF. Pathophysiology and clinical presentations of cough. J Allergy Clin Immunol. 1996;98(5 Pt 2):S91-6 discussion S96-7.

2. Irwin RS, Curley FJ, French CL. Chronic cough. The spectrum and frequency of causes, key components of the diagnostic evaluation, and outcome of specific therapy. Am Rev Respir Dis. 1990;141(3):640-7.

3. Brightling CE. Eosinophils, bronchitis and asthma: pathogenesis of cough and airflow obstruction. Pulm Pharmacol Ther. 2011:24(3):324-7.

4. Diver S, Russell RJ, Brightling CE. Cough and eosinophilia. J Allergy Clin Immunol Pract. 2019:7(6):1740-7.

5. Sadeghi $\mathrm{MH}$, Morice $\mathrm{AH}$. The emerging role of the eosinophil and its measurement in chronic cough. Open Respir Med J. 2017:11:17-30.

6. Sheikh J, Weller PF. Clinical overview of hypereosinophilic syndromes. Immunol Allergy Clin N Am. 2007:27(3):333-55.

7. Roufosse F, Heimann P, Lambert F, Sidon P, Bron D, Cottin V, Cordier JF. Severe prolonged cough as presenting manifestation of FIP1L1-PDGFRA+ chronic eosinophilic leukaemia: a widely ignored association. Respiration. 2016;91(5):374-9.

8. Helbig G, Kyrcz-Krzemien S. Myeloid neoplasms with eosinophilia and FIP1L1-PDGFRA fusion gene: another point of view. Leuk Lymphoma. 2013; 54(4):897-8.

9. Legrand F, Renneville A, Macintyre E, Mastrilli S, Ackermann F, Cayuela JM, et al. The Spectrum of FIP1L1-PDGFRA-associated chronic eosinophilic leukemia: new insights based on a survey of 44 cases. Medicine (Baltimore). 2013:92(5):e1-9.

10. Dulohery MM, Patel RR, Schneider F, Ryu JH. Lung involvement in hypereosinophilic syndromes. Respir Med. 2011;105(1):114-21.

11. Ogbogu PU, Bochner BS, Butterfield JH, Gleich GJ, Huss-Marp J, Kahn JE, et al. Hypereosinophilic syndrome: a multicenter, retrospective analysis of clinical characteristics and response to therapy. J Allergy Clin Immunol. 2009;124(6):1319-25.e3

12. Fauci AS, Harley JB, Roberts WC, Ferrans VJ, Gralnick HR, Bjornson BH. NIH conference. The idiopathic hypereosinophilic syndrome. Clinical, pathophysiologic, and therapeutic considerations. Ann Intern Med. 1982; 97(1):78-92
13. Chusid MJ, Dale DC, West BC, Wolff SM. The hypereosinophilic syndrome: analysis of fourteen cases with review of the literature. Medicine. 1975;54(1):1-27.

14. Spry CJ, Davies J, Tai PC, Olsen EG, Oakley CM, Goodwin JF. Clinical features of fifteen patients with the hypereosinophilic syndrome. Q J Med. 1983; 52(205):1-22.

15. Parrillo JE, Borer JS, Henry WL, Wolff SM, Fauci AS. The cardiovascular manifestations of the hypereosinophilic syndrome. Prospective study of 26 patients, with review of the literature. Am J Med. 1979;67(4): $572-82$.

16. Kobayashi M, Kubota T, Uemura Y, Taguchi H. A case of hypereosinophilic syndrome presenting with chronic cough successfully treated with imatinib. Respirology. 2009;14(2):302-4.

17. Chung KF, Hew M, Score J, Jones AV, Reiter A, Cross NC, Bain BJ. Cough and hypereosinophilia due to FIP1L1-PDGFRA fusion gene with tyrosine kinase activity. Eur Respir J. 2006;27(1):230-2

18. Barker B, Moudgil H, Slocombe G, Srinivasan K. Persistent cough: an unusual cause. Idiopathic hypereosinophilic syndrome (HES). Thorax. 2010;65(11): 1009-24.

19. Messie K, Vovor A, Kueviakoe IM, Sallah LK, Agbetiafa K, Segbena AY. Clonal hypereosinophilic syndrome: two cases report in black men from subsaharan Africa and literature reviews. ISRN Hematol. 2011;2011:974609.

20. Arai A, Yan W, Wakabayashi S, Hayashi S, Inazawa J, Miura O. Successful imatinib treatment of cardiac involvement of FIP1L1-PDGFRA-positive chronic eosinophilic leukemia followed by severe hepatotoxicity. Int J Hematol. 2007;86(3):233-7.

21. Hossain NM, Jain N, Steinmetz JL, McConville JF, Anastasi J, Odenike O. A 32-year-old man with persistent cough, shortness of breath, eosinophilic pneumonia, and peripheral blood eosinophilia. Myeloid neoplasm associated with eosinophilia and platelet-derived growth factor receptoralpha rearrangement. Chest. 2012;142(6):1680-3.

22. Gurgun A, Tuluce K, Tuluce SY, Gurgun C, Bayraktaroglu S, Tombuloglu M, Cinar CS. Hypereosinophilic syndrome presenting with large left ventricular apical thrombus and pulmonary embolism. Echocardiography. 2011;28(9): E180-2.

23. Slabbynck H, Impens N, Naegels S, Dewaele M, Schandevyl W. Idiopathic hypereosinophilic syndrome-related pulmonary involvement diagnosed by bronchoalveolar lavage. Chest. 1992;101(4):1178-80.

24. Karnak D, Kayacan O, Beder S, Delibalta M. Hypereosinophilic syndrome with pulmonary and cardiac involvement in a patient with asthma. CMAJ. 2003;168(2):172-5.

25. Wojciechowska C, Gala A, Kuczaj A, Jachec W, Foremny A, Helbig G, Wojnicz $\mathrm{R}$, Nowalany-Kozielska E. Heart failure mimicking prior myocardial infarction in a patient with idiopathic hypereosinophilic syndrome. Int Heart J. 2011; 52(3):194-6

26. Osowo A, Fetten J, Navaneethan S. Idiopathic hypereosinophilic syndrome: a rare but fatal condition presenting with common symptoms. South Med J. 2006;99(2):188-9.

27. Goldman MH, Bochner BS, Essayan DM. Cough, shortness of breath, and eosinophilia in a 68-year-old man. Ann Allergy Asthma Immunol. 1996;77(3): $177-83$

28. Klion AD. How I treat hypereosinophilic syndromes. Blood. 2015;126(9): 1069-77.

29. Klion AD, Robyn J, Akin C, Noel P, Brown M, Law M, Metcalfe DD, Dunbar C, Nutman TB. Molecular remission and reversal of myelofibrosis in response to imatinib mesylate treatment in patients with the myeloproliferative variant of hypereosinophilic syndrome. Blood. 2004;103(2):473-8.

30. Pardanani A, Reeder T, Porrata LF, Li CY, Tazelaar HD, Baxter EJ, Witzig TE, Cross NC, Tefferi A. Imatinib therapy for hypereosinophilic syndrome and other eosinophilic disorders. Blood. 2003;101(9):3391-7.

31. Butt NM, Lambert J, Ali S, Beer PA, Cross NC, Duncombe A, et al. Guideline for the investigation and management of eosinophilia. Br J Haematol. 2017; 176(4):553-72.

32. Pitini V, Arrigo C, Azzarello D, La Gattuta G, Amata C, Righi M, Coglitore S. Serum concentration of cardiac troponin $T$ in patients with hypereosinophilic syndrome treated with imatinib is predictive of adverse outcomes. Blood. 2003;102(9):3456-7.

33. Khoury P, Desmond R, Pabon A, Holland-Thomas N, Ware JM, Arthur DC, Kurlander R, Fay MP, Maric I, Klion AD. Clinical features predict responsiveness to imatinib in platelet-derived growth factor receptor-alphanegative hypereosinophilic syndrome. Allergy. 2016;71(6):803-10. 
34. Klion AD, Noel P, Akin C, Law MA, Gilliland DG, Cools J, Metcalfe DD, Nutman TB. Elevated serum tryptase levels identify a subset of patients with a myeloproliferative variant of idiopathic hypereosinophilic syndrome associated with tissue fibrosis, poor prognosis, and imatinib responsiveness. Blood. 2003;101(12):4660-6

35. Haldar P, Brightling CE, Hargadon B, Gupta S, Monteiro W, Sousa A, et al. Mepolizumab and exacerbations of refractory eosinophilic asthma. N Engl J Med. 2009;360(10):973-84.

36. Niimi A, Brightling CE, Dicpinigaitis PV. Cough in asthma is due to eosinophilic airway inflammation: a pro/con debate. Lung. 2014;192(1):33-8.

\section{Publisher's Note}

Springer Nature remains neutral with regard to jurisdictional claims in published maps and institutional affiliations.

Ready to submit your research? Choose BMC and benefit from:

- fast, convenient online submission

- thorough peer review by experienced researchers in your field

- rapid publication on acceptance

- support for research data, including large and complex data types

- gold Open Access which fosters wider collaboration and increased citations

- maximum visibility for your research: over $100 \mathrm{M}$ website views per year

At BMC, research is always in progress.

Learn more biomedcentral.com/submissions 